Categoria

Trabalho Acadêmico\Resumo Expandido

Titulo do Trabalho

\title{
AVALIAÇÃO DO ÍNDICE DE QUALIDADE DA ÁGUA (IQA) NA \\ MICROBACIA DO CÓRREGO CAÇULA NO MUNICÍPIO DE ILHA \\ SOLTEIRA/SP - DADOS PRELIMINARES
}

Nome da Autora Principal

Letícia de Oliveira Manoel

Nome do Co-autor

Sérgio Luís de Carvalho

Nome do Orientador

Prof. Dr. Sérgio Luís de Carvalho

Instituição ou Empresa

Universidade Estadual Paulista “Júlio de Mesquita Filho”-UNESP-FEIS

Instituição (s) de Fomento

Capes

E-mail de contato

leticia.is@gmail.com.br

Palavras-chave

Bacia hidrográfica. Ocupação do solo. Recursos hídricos 


\section{INTRODUÇÃO}

O crescimento demográfico e o desenvolvimento socioeconômico são frequentemente acompanhados de aumentos na demanda por água, cuja quantidade e qualidade são de fundamental importância para a saúde e o desenvolvimento de qualquer comunidade (BUENO et al., 2005).

No Brasil, o problema não está na quantidade de água disponível, uma vez que é um país privilegiado neste aspecto, mas sim na qualidade desta água, reflexo de um passado de gestão inadequada. Deste modo, há a necessidade de um manejo adequado dos recursos hídricos, de forma a garantir a água na quantidade e na qualidade desejáveis aos seus múltiplos usos (LEITÃO, 2001).

Assim, para assegurar o gerenciamento sustentado dos recursos hídricos e seus múltiplos usos, a avaliação da qualidade da água numa bacia hidrográfica é de fundamental importância (STRIEDER et al., 2006).

Para a interpretação da qualidade das águas superficiais, é necessária a utilização de métodos simples. Para isso, o uso de índices de qualidade de água é uma alternativa que todo programa de monitoramento de águas superficiais prevê, para acompanhar, de forma resumida, a possível deterioração dos recursos hídricos ao longo da bacia hidrográfica ou ao longo do tempo (TOLEDO e NICOLELLA, 2002). O uso de indicadores físico-químicos da qualidade da água consiste no emprego de variáveis que se correlacionam com as alterações ocorridas na microbacia, sejam essas de origem antrópica ou natural (DONADIO et al., 2005).

\section{OBJETIVO GERAL}

O objetivo desta pesquisa é avaliar a qualidade da água na microbacia do Córrego Caçula, por meio do monitoramento de parâmetros físico-químicos e biológicos, utilizando-se o Índice de Qualidade da Água (IQA). 


\section{METODOLOGIA}

As coletas de água foram realizadas de maio a setembro de 2012, com periodicidade mensal, na microbacia do Córrego Caçula, no município de Ilha Solteira SP, compreendendo cinco pontos de amostragem: P1 - nascente do Córrego do Ipê, P2 nascente do Córrego da Lagoa, P3 - na Foz do Córrego da Lagoa, P4 - Foz do córrego do Ipê e P5 - Córrego Caçula. A Tabela 1 localiza os pontos de amostragem na microbacia do Córrego Caçula.

Tabela 1 - Localização dos pontos de amostragem

\begin{tabular}{cccccc}
\hline Ponto & Latitude & Longitude & Altitude $(\mathbf{m})$ & $\begin{array}{c}\text { Uso } \\
\text { Localização }\end{array}$ & $\begin{array}{c}\text { Uso } \\
\text { predominante } \\
\text { do solo }\end{array}$ \\
\hline 1 & $20^{\circ} 27^{\prime} 25.4^{\prime \prime}$ & $51^{\circ} 18^{\prime} 33.7^{\prime \prime}$ & 366 & Nascente do Córrego do Ipê & Agrícola e Urbano \\
2 & $20^{\circ} 29^{\prime} 310^{\prime \prime}$ & $51^{\circ} 17^{\prime} 17.4^{\prime \prime}$ & 365 & Nascente do Córrego da Lagoa & Agrícola \\
3 & $20^{\circ} 27^{\prime} 05.3^{\prime \prime}$ & $5^{\circ} 21^{\prime} 45.8^{\prime \prime}$ & 288 & Foz do Córrego da Lagoa & Agrícola \\
4 & $20^{\circ} 27^{\prime} 05.2^{\prime \prime}$ & $51^{\circ} 21^{\prime} 46.8^{\prime \prime}$ & 289 & Foz do Córrego do lpê & Agrícola e Urbano \\
5 & $20^{\circ} 27^{\prime} 08.9^{\prime \prime}$ & $51^{\circ} 21^{\prime} 53,4^{\prime \prime}$ & 285 & Foz do Córrego Caçula & Agrícola \\
\hline
\end{tabular}

Para avaliações da qualidade da água, foi utilizado o índice de qualidade de água (IQA) de acordo com CETESB (2007). O IQA foi calculado utilizando-se as variáveis físicas, químicas e biológicas, com base nos Métodos para as Análises de Águas Potáveis e Residuárias - Standard Methods for Examination of Water and Wastewater (APHAAWWA-WPCF,1998) e pela metodologia de espectrofotometria de Hach, para os seguintes parâmetros: análises físicas (Turbidez (UT) e Temperatura $\left({ }^{\circ} \mathrm{C}\right)$ ), químicas $(\mathrm{pH}$, Nitrogênio Total $(\mathrm{mg} / \mathrm{L})$, Fósforo Total $(\mu \mathrm{g} / \mathrm{L})$, Demanda Bioquímica de Oxigênio DBO (mg/L), Oxigênio Dissolvido OD ( $\mathrm{mg} / \mathrm{L})$, Sólidos Totais $(\mathrm{mg} / \mathrm{L})$ ) e biológicas (Coliforme Termo tolerante $(\mathrm{NMP} / 100 \mathrm{ml})$. As amostras foram analisadas no laboratório de Saneamento do Departamento de Engenharia Civil da Faculdade de Engenharia de Ilha Solteira (UNESP). 
O IQA é calculado pelo produtório ponderado das qualidades de água correspondentes às variáveis que integram o índice. As seguintes equações (1 e 2) foram utilizadas:

$$
\mathrm{IQA}=\prod_{\mathrm{i}=1}^{\mathrm{n}} \mathrm{q}_{\mathrm{i}}^{\mathrm{w}_{\mathrm{i}}}
$$

Onde:

IQA: Índice de Qualidade das Águas, um número entre 0 e 100;

$q_{i}$ : qualidade do i-ésimo parâmetro, que varia entre 0 e 100, obtido da respectiva "curva média de variação de qualidade", em função de sua concentração ou medida, e $\mathbf{w}_{\mathrm{i}}$ : peso correspondente ao i-ésimo parâmetro, que varia entre 0 e 1, atribuído em função da sua importância para a conformação global de qualidade, sendo que:

$$
\sum_{i=1}^{n} w_{i}=1
$$

em que:

n: número de variáveis que entram no cálculo do IQA,

$\mathbf{w}_{\mathrm{i}}$ : peso correspondente ao i-ésimo parâmetro, que varia entre 0 e 1.

A partir do cálculo efetuado, pode-se determinar a qualidade das águas brutas, que é indicada pelo IQA, variando numa escala de 0 a 100, mostrada no Quadro 1.

Quadro 1. Escala de qualidade da água indicada pelo IQA

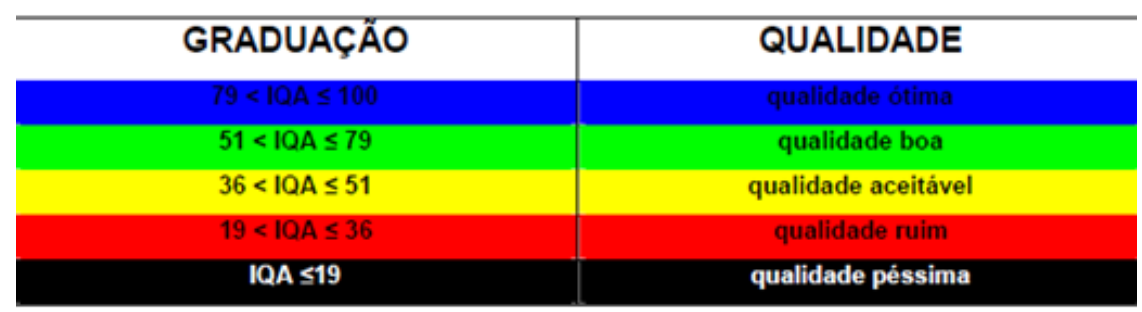

FONTE: Adaptado CETESB (2001)

\section{RESULTADOS}


Baseando-se na classificação do IQA para os cinco meses de estudo, verificou-se que os comportamentos desses índices foram semelhantes em relação aos pontos de coleta. Embora preliminar para o período de monitoramento, as águas do ponto P3 apresentaram os melhores resultados de IQA (média de 77,4; classificando a água como de boa qualidade). No P1, P2, P4 e P5 o IQA apresentou médias de 61,2; 55; 60,2 e 64,4 respectivamente, classificando a água como de boa qualidade (Figura 2).

Estes resultados estão coerentes com a localização dos pontos, pois o P1 e P2 referem-se à região da nascente, local ainda preservado, enquanto os pontos P4 e P5 podem ter sido influenciados por fontes pontuais de contaminação.

Figura 2. Representação gráfica dos resultados de IQA na microbacia do Córrego Caçula

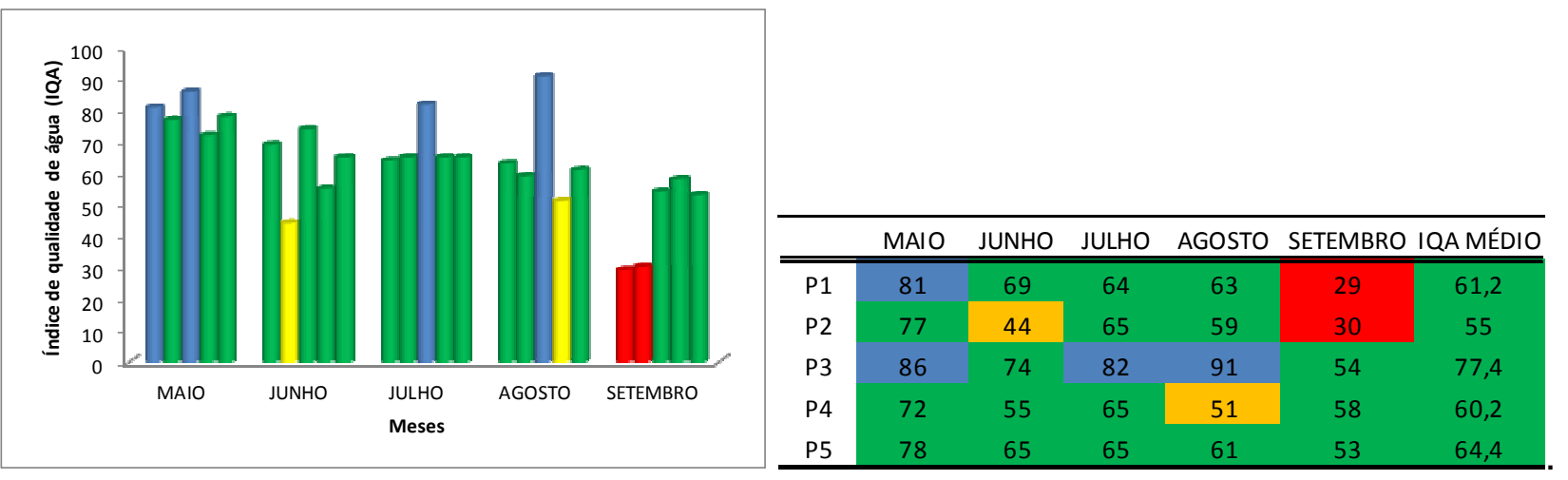

FONTE: Do próprio autor

\section{CONSIDERAÇÕES FINAIS}

Neste estudo, de acordo com os resultados de IQA, embora preliminares para os meses estudados e pontos estudados, a qualidade da água foi boa, sendo ótima apenas para os meses de maio no (P1) e (P3) e julho e agosto no (P3). Os resultados obtidos de IQA, na presente pesquisa, são semelhantes aos apresentados por Poleto (2003) e Ortega (2011) para o Córrego do Ipê. Neste estudo, a média de IQA ao longo da 
Microbacia do Córrego Caçula, envolvendo os cinco pontos estudados, foi de 63,6 embora algumas variáveis como oxigênio dissolvido (junho, agosto e setembro), coliformes fecais (agosto e setembro) e fósforo (agosto e setembro) tenham ultrapassado os valores estabelecidos pela Resolução CONAMA 357/05 para rio de classe 2. Dessa forma, fica evidenciada a importância da gestão dos recursos hídricos na bacia estudada.

\section{REFERÊNCIAS}

APHA, AWWA, WPCF. Standard methods for the examination of water and wastewater. $20^{\text {th }}$ ed. Washington, DC: APHA, 1998.

CETESB. COMPANHIA ESTADUAL DE TECNOLOGIA DE SANEAMENTO BÁSICO E DEFESA DO MEIO AMBIENTE. Água: rios e reservatórios. Disponível em: <http://www.cetesb.sp.gov.br/agua/rios/indice.asp>. Acesso em: 30 set. 2012.

CETESB. COMPANHIA ESTADUAL DE TECNOLOGIA DE SANEAMENTO BÁSICO E DEFESA DO MEIO AMBIENTE. Relatório de qualidade das águas interiores do Estado de São Paulo 2000. São Paulo, 2001. v.1, 214 p.

BUENO, L.F.; GALBIATTI, J.A.; BORGES, M.J. Monitoramento de variáveis de qualidade de água no horto Ouro Verde - Conchal - SP. Engenharia Agrícola, Jaboticabal, v.25, n.3, p.742-748, 2005.

CONSELHO NACIONAL DO MEIO AMBIENTE, Resolução CONAMA 357/05: Estabelecer a classificação das águas, doces, salobras e salinas do Território Nacional. Brasília-DF, 2005.

DONADIO, N.M.M.; GALBIATTI, J.A.; PAULA, R.C.de. Qualidade da água de nascentes com diferentes usos do solo na bacia hidrográfica do Córrego Rico, São Paulo, Brasil. Engenharia Agrícola, Jaboticabal, v.25, n.1, p.115-125, 2005.

LEITÃO, S. M. A Visão da Água: O Desafio do Milênio. Ecolatina 2001. Belo Horizonte, MG, 2001.

Ortega, D. J.P. Avaliação dos efeitos das atividades antrópicas na bacia hidrográfica do Córrego do Ipê, município de Ilha Solteira - SP. 2011. 151 f. Dissertação (Mestrado em Engenharia Civil) - Faculdade de Engenharia de Ilha Solteira, Universidade Estadual Paulista,Ilha Solteira, 2011. 
POLETO, C. Monitoramento e avaliação da qualidade da água de uma microbacia hidrográfica no município de Ilha Solteira-SP. 2003. 101 f. Dissertação (Mestrado em Engenharia Civil) - Faculdade de Engenharia de Ilha Solteira, Universidade Estadual Paulista, Iha Solteira, 2003.

STRIEDER, M.N.; RONCHI, L.H.; STENERT, C.; SCHERER, R.T.; NEISS, U.G. Medidas biológicas e índices de qualidade da água de uma microbacia com poluição urbana e de curtumes no Sul do Brasil. Acta Biológica Leopoldensia, Porto Alegre, v.28, n.1, p.17-24, 2006.

TOLEDO, L.G. de; NICOLELLA, G. Índice de qualidade de água em microbacia sob uso agrícola e urbano. Scientia Agrícola, Piracicaba, v.59, n.1, p.181-186, 2002. 